\title{
Specification of the nervous system ${ }^{*}$
}

\author{
Oliver Hobert ${ }^{\S}$, Howard Hughes Medical Institute, Department of \\ Biochemistry and Molecular Biophysics, Columbia University Medical \\ Center, New York, NY 10032 USA
}

\section{Table of Contents}

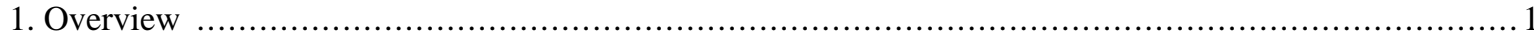

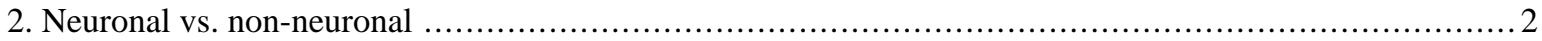

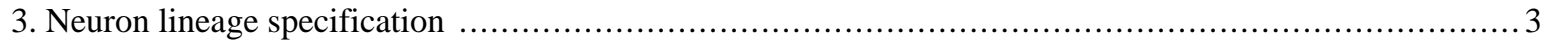

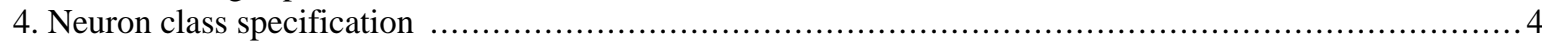

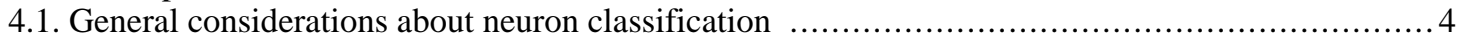

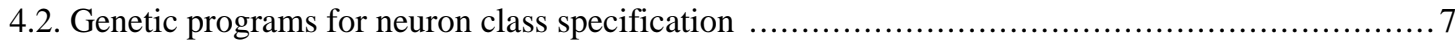

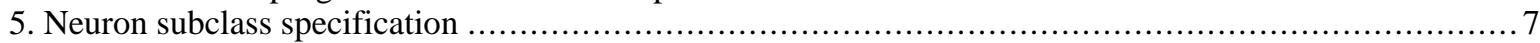

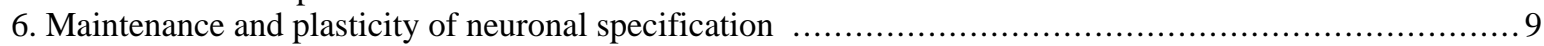

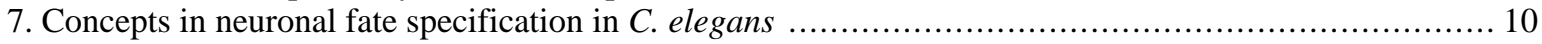

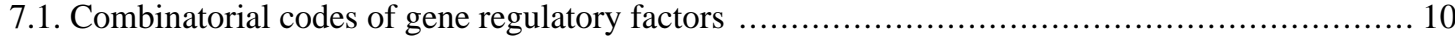

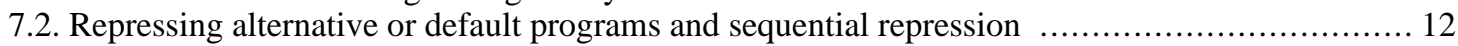

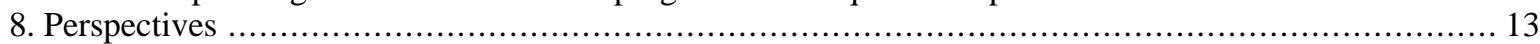

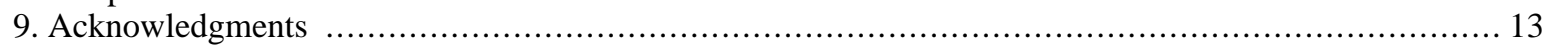

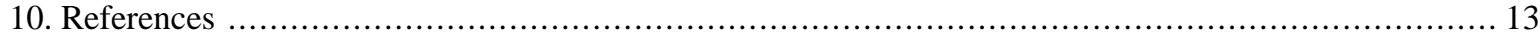

\begin{abstract}
Nervous systems are characterized by an astounding degree of cellular diversity. The nematode Caenorhabditis elegans has served as a valuable model system to define the genetic programs that serve to generate cellular diversity in the nervous system. This review discusses neuronal diversity in $C$. elegans and provides an overview of the molecular mechanisms that define and specify neuronal cell types in $C$. elegans.
\end{abstract}

\section{Overview}

The nervous system represents the most complex organ of $C$. elegans. It is the organ with the most cells (302 neurons and 56 glial cells make up $37 \%$ of the somatic cells in a hermaphrodite) and the largest cellular diversity (at least 118 different neuron classes). Its cellular complexity makes the $C$. elegans nervous system a prime model system to study a central question in developmental neurobiology, namely how neuronal diversity is genetically programmed. This question can be broken down into four separate steps that will be discussed in this chapter. First,

\footnotetext{
${ }^{*}$ Edited by Erik M. Jorgensen and Joshua M. Kaplan. Last revised July 22, 2005. Published August 8, 2005. This chapter should be cited as: Hobert, O. Specification of the nervous system (August 8, 2005), WormBook, ed. The C. elegans Research Community, WormBook, doi/10.1895/wormbook.1.12.1, http://www.wormbook.org.

Copyright: () 2005 Oliver Hobert. This is an open-access article distributed under the terms of the Creative Commons Attribution License, which permits unrestricted use, distribution, and reproduction in any medium, provided the original author and source are credited

${ }^{\S}$ To whom correspondence should be addressed. E-mail: or38@columbia.edu
} 
a cell must make a global choice between neuronal and non-neuronal fate. Second, specific neuronal lineage decisions must be made. Third, neurons must be instructed to terminally differentiate into specific classes after their last cell division. Fourth, within defined classes of neurons that share many different properties, subtle but critical differences between individual class members must be established. I will give a brief summary and several examples of molecular mechanisms that are involved in neuronal specification on these levels. Rather than comprehensively discussing all known neuronal specification genes, I will try to carve out a few general principles of neuronal specification, using selected examples. Many aspects of neuron specification in C. elegans have been discussed in several previous reviews to which the reader is referred for more in-depth discussions (Ruvkun, 1997; Melkman and Sengupta, 2004).

\section{Neuronal vs. non-neuronal}

At first sight, perhaps the most striking difference between neuronal specification in C. elegans and many other well characterized systems concerns the lineage history of individual neurons. While in many species the nervous system originates from defined precursor cells in specific regions of the developing embryo, a brief look at the lineage of $C$. elegans illustrates, strikingly, that $C$. elegans neurons are largely non-clonally derived from many different lineages (Figure 1). However, in analogy to vertebrate neuronal development (Hemmati-Brivanlou and Melton, 1997), it is conceivable that non-neuronal cells produced within largely neuron-producing lineages may be derived from a "neuronal ground state", which would be actively repressed in non-neuronal cells. Consistent with such a notion, mutants have been described in which non-neuronal cells "revert" to a neuronal fate. For example, in animals that lack the basic helix-loop-helix (bHLH) factor lin-22 or the Zn finger transcription factor lin-26, specific sets of hypodermal cells inappropriately adopt a neuronal fate (Horvitz et al., 1983; Labouesse et al., 1994; Wrischnik and Kenyon, 1997; Figure 2A, B). Moreover, depletion of the transcriptional co-factor $p 300 / c b p-1$ de-represses neuronal fate in many cell types (Shi and Mello, 1998). Lastly, an embryonic induction mediated by the Notch gene $g l p-l$ can be considered a diversification from a neuronal ground state; in the absence of this induction both bilaterally homologous $\mathrm{ABara}$ and $\mathrm{ABala}$ lineages produce only neurons, while in the presence of $g l p-1$, the ABara lineage produces neuronal and non-neuronal cells (Hutter and Schnabel, 1994). Taken together, in analogy to the vertebrate system, neuronal fate may be the "default" specification program in many lineages that is modified through the action of specific gene products.
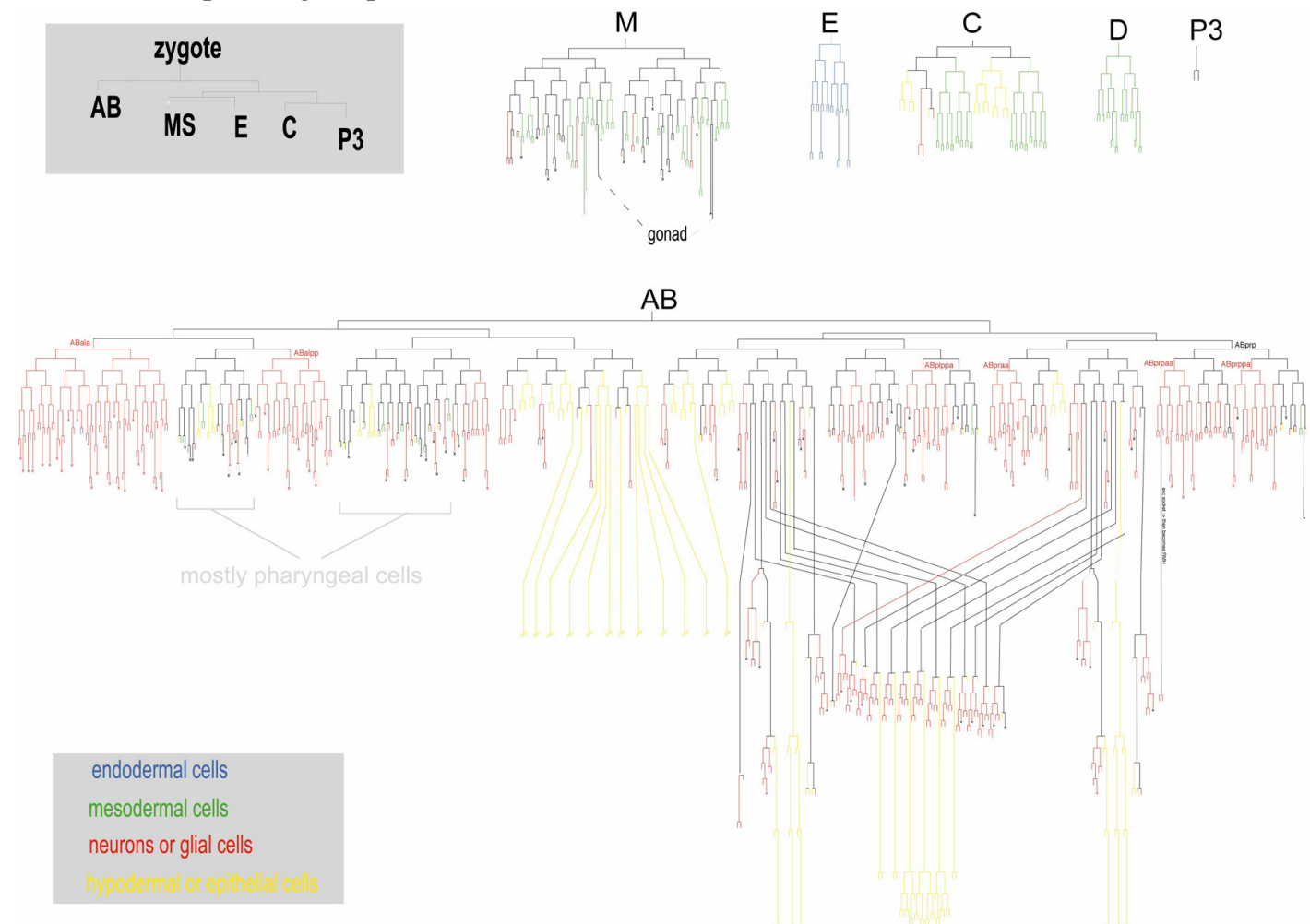

Figure 1. Location of neurons in the lineage diagram. Upper left panels indicate embryonic blastomeres. All other lineages are descendants of these blastomeres. Strike-through indicate that the lineage has not been drawn out to completion. After Sulston et al., 1983. Right-click or control click for high resolution image. 


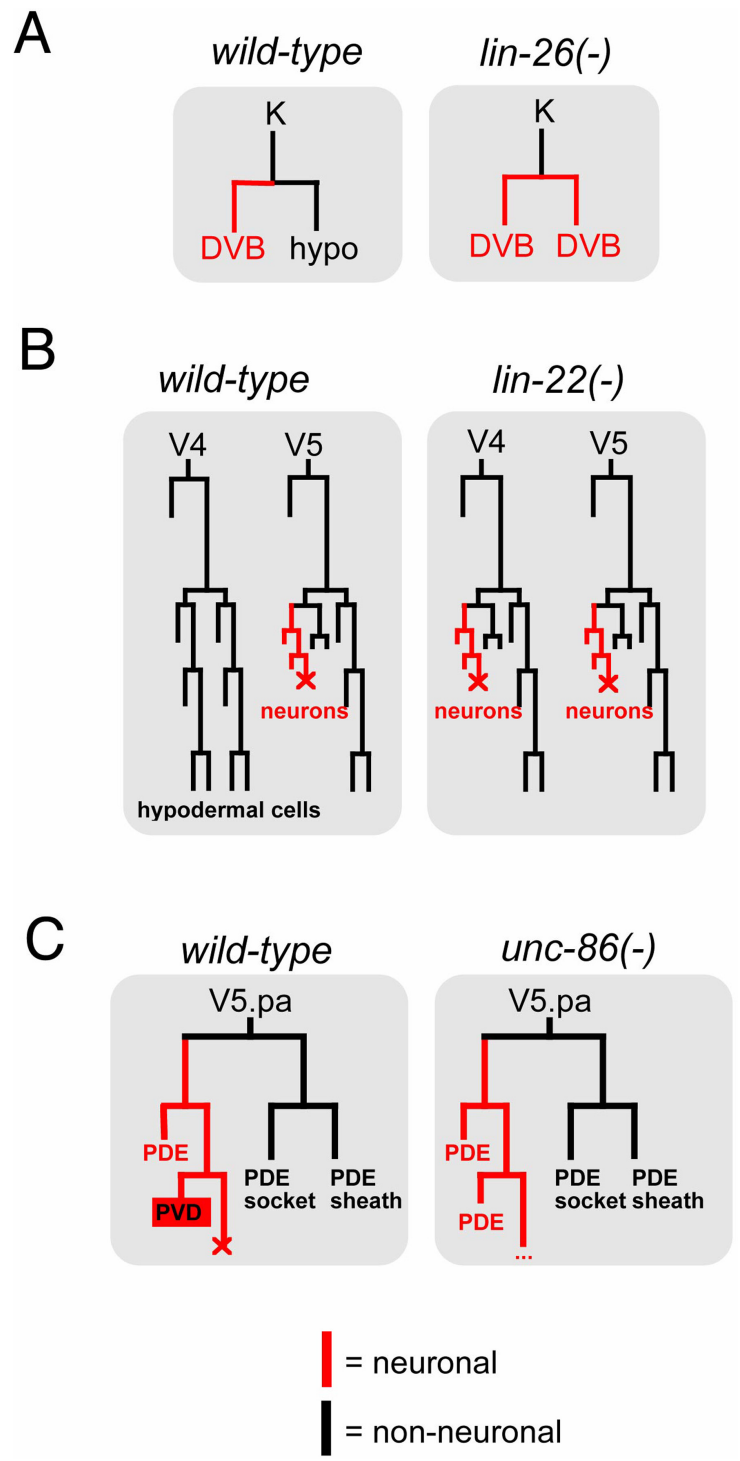

Figure 2. Lineage transformations in specific mutant backgrounds. (A) A hypodermal cell transforms into a motorneuron (DVB) in lin-26 mutants (Horvitz et al., 1983). (B) Hypodermal cells derived from the postembryonic V ectoblasts transform into neuronal fates in lin-22 mutants (Horvitz et al., 1983). (C) The V5.pa lineage branch exclusively produces parts of a sensory sensillum (PDE neurons, sheath and socket cells) in the absence of unc-86. unc-86 gene activity determines that the functionally unrelated PVD sensory neuron is generated (Horvitz et al., 1983).

\section{Neuron lineage specification}

Once a lineage is fated to produce neurons, several genes are required to determine the type of neuronal lineage program that is executed. Consequently, in the absence of these genes, neuroblasts are either not specified correctly or undergo aberrant lineage patterns. Genes that fall into this category include the classic examples of the unc-86 homeobox gene and the lin-32 bHLH gene (reviewed in Ruvkun, 1997); more recently described examples include the C. elegans NeuroD homolog cnd-l (Hallam et al., 2000), the daughterless homolog hlh-2 (Portman and Emmons, 2000) and the pag-3 Zn finger factor (Cameron et al., 2002). While all genes in this category act by definition in neuroblasts to affect descendants of these blast cells, it is notable that some of the genes have also later roles in terminal neuron differentiation. For example, unc-86 affects the lineage that generates the touch sensory neurons, but also acts in the mature touch neurons to directly regulate the expression of terminal differentiation features (Chalfie and Sulston, 1981; Duggan et al., 1998). A similar scenario holds for the lin-32 and hlh-2 bHLH genes (Portman and Emmons, 2000). Re-utilization, or co-option, of transcription factors in different contexts is a common theme in many developmental pathways. 


\section{Neuron class specification}

\subsection{General considerations about neuron classification}

If one wishes to discuss the genetic specification of individual neuron classes, it is important to first consider what defines a neuron class. The most trivial classification of neurons divides them into sensory, inter- and motorneurons. However, there is little lineage relation among neurons that are predominantly of the sensory-, interor motorneuron type in $C$. elegans. That is, there is no defined neuroblast that exclusively produces each class. Nevertheless, genetic analysis has revealed two common genetic specification programs. The daf-19 transcription factor was found to be required for the development of specific differentiated aspects of all ciliated sensory neurons, even though most of them are unrelated by lineage (Swoboda et al., 2000). The cnd-1 bHLH transcription factor is required for ventral nerve cord (VNC) motorneuron specification (Hallam et al., 2000). These observations indicate that daf-19 and cnd-1 may sample lineage specific cues (e.g. by having complex promoters, responsive to transcription factors produced in different lineages) to drive a specific type of differentiation program in cells derived from distinct lineages.

Another broadly applied classification of neurons is based on the type of neurotransmitter that a neuron produces ("neurotransmitter phenotype"). However, C. elegans neurons with the same neurotransmitter phenotype show little if any lineage relation. Also, there are as yet no common specification programs identified for the complete set of neurons classified by neurotransmitter phenotypes. Rather, the neurons in this classification scheme appear to be generated in a "mosaic" manner, best illustrated by the 26 GABAergic neurons. Two defining features of GABAergic neurons are their production of a GABA-producing enzyme (unc-25) and a vesicular GABA transporter (unc-47). GABAergic ventral cord motorneurons require the transcription factor unc-30 to express unc-25 and unc-47 (Jin et al., 1994; Eastman et al., 1999). However, other GABAergic neurons do not express unc-30 and require a different set of transcription factors to express the GABAergic phenotype. For example, the GABAergic DVB and AVL neurons require the homeobox gene lim- 6 to express unc-25, but not unc-47 (Hobert et al., 1999). Although expressing lim-6, the RME neuron class does not require lim-6 to express the GABAergic fate.

Another classification of neurons that relates directly to neuronal specification goes along the lines of functional units. In the fly nervous system, neurons and support cells that form a sensory sensillum derive from a common sublineage that are jointly specified by gene regulatory programs (Modolell, 1997). In contrast, cells that form specific types of sensory sensilla in worms (neuron, sheath, socket) rarely have a common lineage history (Figure 1) with the notable exception of the postdeirid sensory sensillum (Figure 2C). The V5.pa neuroblast creates a sensory neuron, PDE, its sheath (PDEsh) and socket (PDEso), but also a different type of sensory neuron, PVD. Hence, the V5.pa lineage is not specialized to exclusively produce components of a sensory sensillum. However, genetic removal of the unc- 86 homeobox gene causes the aberrant production of an extra PDE neuron at the expense of the PVD neuron (Chalfie and Sulston, 1981; Figure 2C). Therefore, the lineage is now transformed to only produce sensory sensillum components. It is perhaps a common principle that there is an underlying, perhaps ancient, relationship between cells of a given lineage branch (in the case of the V5.pa lineage branch, a sensory sensillum fate), but transcriptional regulators (e.g., unc-86) are "superimposed" onto this lineage to diversify individual cell types within this lineage. This is the same principle as mentioned above for neuronal vs. non-neuronal fate programs; the latter may be superimposed onto a neuronal ground state.

A more refined classification of neuronal cell types does not go along the lines of sensory vs. inter vs. motorneuron, but rather makes use of classifying neurons based on specific anatomical features, such as axodendritic morphology, cell body placement and synaptic connectivity. Based on their electron microscopy work, White et al. defined 118 neuron classes (White et al., 1986), with members of individual neuron classes mostly distinguished by their relative position to the anterior/posterior or left/right axis (for examples, please see WormAtlas: www.wormatlas.org/neurons.htm/aiy.htm and www.wormatlas.org/neurons.htm/rme.htm). Our understanding of the genetic mechanisms of neuronal specification on this single class level is extensive for

individual cases and examples are summarized in Table 1. The overall emerging scheme is that each of these neuron types have their own "specification cassette", that is, a set of gene regulatory factors that specifies individual fates, as described in the next section. 
Table 1. Gene regulatory factors that control neuron class specification. Genes are grouped into three different categories according to the defects that are caused by their absence ("All known features lost", "Subfeatures lost", "Alternative or default program executed"). Categorization can only be made within the limitations of current knowledge, meaning the current extent to which neuron properties are known and have been examined in the individual mutants. For example, at present it can not be excluded that a gene such as $t t x-3$ controls hundreds of, but not quite all AIY-defining genes. Also note that this list is not comprehensive. Examples that do not clearly fall into any of these categories are also not shown. Ubiquitously expressed co-factors that affect specific neuronal differentiation events by interacting with cell-type specific transcription factors, such as unc-37 or lin-49 and others, are not shown here. Transcription factors that broadly affect embryonic patterning, therefore obscuring any potential neuronal specification role, or factors that may affect neuronal specification indirectly are also not shown.

\begin{tabular}{|c|c|c|c|c|}
\hline Defect & $\begin{array}{l}\text { Gene } \\
\text { name }\end{array}$ & Gene class & Neurons affected & Reference \\
\hline \multirow{13}{*}{$\begin{array}{l}\text { All known } \\
\text { features lost }\end{array}$} & ceh-36 & Homeobox & AWC sensory neurons & $\begin{array}{l}\text { Lanjuin et al., 2003; } \\
\text { Koga and Ohshima, 2004 }\end{array}$ \\
\hline & ceh-37 & Homeobox & AWB sensory neurons & Lanjuin et al., 2003 \\
\hline & che-1 & $\mathrm{Zn}$ finger & ASE sensory neurons & Chang et al., 2003; Uchida et al., 2003 \\
\hline & $\begin{array}{l}\text { egl-44, } \\
\text { egl-46 }\end{array}$ & $\begin{array}{l}\text { Zn-finger and } \\
\text { TEF-type }\end{array}$ & HOB sensory neurons & Yu et al., 2003 \\
\hline & $\operatorname{lin}-11$ & LIM homeobox & $\begin{array}{l}\text { AWA sensory neurons } \\
\text { AVG interneuron }\end{array}$ & Sarafi-Reinach et al., 2001; Hutter, 2003 \\
\hline & $\lim -4$ & LIM homeobox & AWB sensory neurons & Sagasti et al., 1999 \\
\hline & mec-3 & LIM homeobox & Touch neurons & $\begin{array}{l}\text { Way and Chalfie, 1988; } \\
\text { Zhang et al., } 2002\end{array}$ \\
\hline & $o d r-7$ & $\begin{array}{l}\text { Nuclear } \\
\text { hormone } \\
\text { receptor }\end{array}$ & AWA sensory neurons & Sengupta et al., 1994 \\
\hline & $t t x-1^{\mathrm{a}}$ & Homeobox & AFD sensory neurons & Satterlee et al., 2001 \\
\hline & $t t x-3$ & LIM homeobox & AIY interneurons & Hobert et al., 1997 \\
\hline & unc-30 & Homeobox & D-type motorneurons & Jin et al., 1994 \\
\hline & unc-86 & POU homeobox & Many & $\begin{array}{c}\text { Finney et al., 1988; } \\
\text { Finney and Ruvkun, 1990; } \\
\text { Sze et al., 2002 }\end{array}$ \\
\hline & unc-130 & Forkhead & ASG sensory neurons & Sarafi-Reinach and Sengupta, 2000 \\
\hline \multirow{8}{*}{$\begin{array}{l}\text { Subfeatures } \\
\text { lost }\end{array}$} & ceh-2 & Homeobox & M3 motorneuron & Aspock et al., 2003 \\
\hline & ceh-10 & Homeobox & CAN neuron ${ }^{b}$ & Forrester et al., 1998 \\
\hline & ceh-14 & Homeobox & AFD sensory neurons & Cassata et al., 2000 \\
\hline & ceh-17 & Homeobox & ALA, SIA neurons & Pujol et al., 2000 \\
\hline & ceh-23 & Homeobox & AIY interneurons & Altun-Gultekin et al.,2001 \\
\hline & egl-5 & HOX cluster & HSN motorneurons & Desai et al., 1988 \\
\hline & $\begin{array}{l}\text { egl-43, } \\
\text { ham-2 }\end{array}$ & Zn finger & HSN motorneurons & Baum et al., 1999 \\
\hline & fax -1 & $\begin{array}{l}\text { Nuclear } \\
\text { hormone } \\
\text { receptor }\end{array}$ & AVK interneurons & Much et al., 2000 \\
\hline
\end{tabular}




\begin{tabular}{|c|c|c|c|c|}
\hline Defect & $\begin{array}{l}\text { Gene } \\
\text { name }\end{array}$ & Gene class & Neurons affected & Reference \\
\hline \multirow{8}{*}{$\begin{array}{l}\text { Subfeatures } \\
\text { lost }\end{array}$} & lin-11 & LIM homeobox & $\begin{array}{l}\text { AIZ interneurons, VC } \\
\text { motorneurons }\end{array}$ & Hobert et al., 1998 \\
\hline & $\begin{array}{l}\text { lin-39, } \\
m a b-5\end{array}$ & HOX cluster & Q neuroblasts & Kenyon, 1986; Clark et al., 1993 \\
\hline & $\lim -4$ & LIM homeobox & RID motorneuron & Tsalik et al., 2003 \\
\hline & lim-6 & LIM homeobox & $\begin{array}{l}\text { DVB motorneuron, } \\
\text { RIS interneuron }\end{array}$ & $\begin{array}{l}\text { Hobert et al., 1999; } \\
\text { Tsalik et al., } 2003\end{array}$ \\
\hline & $t t x-3$ & LIM homeobox & AIA interneurons & Altun-Gultekin et al., 2001 \\
\hline & unc-3 & Zn finger & $\begin{array}{l}\text { ASI, ventral cord } \\
\text { motorneurons }\end{array}$ & Prasad et al., 1998 \\
\hline & unc- 42 & Homeobox & $\begin{array}{l}\text { Command interneurons, } \\
\text { RMD motorneurons, } \\
\text { ASH sensory neurons }\end{array}$ & Baran et al., 1999; Brockie et al., 2001 \\
\hline & $z a g-1$ & Zn finger & Many neurons & $\begin{array}{l}\text { Clark and Chiu, 2003; } \\
\text { Wacker et al., } 2003\end{array}$ \\
\hline \multirow{14}{*}{$\begin{array}{l}\text { Alternative or } \\
\text { "default" } \\
\text { program } \\
\text { executed }\end{array}$} & $a h r-1$ & Zn finger & $\begin{array}{l}\text { RMED/V vs. RMEL/R } \\
\text { motorneurons }\end{array}$ & Huang et al., 2004 \\
\hline & $\begin{array}{l}\text { ceh-36, } \\
\text { cog-1, } \\
\lim -6\end{array}$ & Homeobox & \multirow{3}{*}{ ASEL vs. ASER } & \multirow{3}{*}{$\begin{array}{l}\text { Chang et al., 2003; } \\
\text { Johnston and Hobert, 2003; } \\
\text { Chang et al., } 2004\end{array}$} \\
\hline & die-1 & Zn finger & & \\
\hline & $\begin{array}{l}\text { lsy-6, } \\
\text { mir-273 }\end{array}$ & miRNA & & \\
\hline & $c f i-1$ & ARID & $\begin{array}{l}\text { URA vs.CEM sensory } \\
\text { neurons }\end{array}$ & Shaham and Bargmann, 2002 \\
\hline & $\begin{array}{l}e g l-5, \\
m a b-5\end{array}$ & HOX gene & \multirow[t]{2}{*}{ Male sensory rays } & \multirow[t]{2}{*}{ Lints et al., 2004} \\
\hline & $m a b-18$ & Pax gene & & \\
\hline & egl-44 & TEF-family & \multirow[b]{2}{*}{ Represses touch fate } & Wu et al., 2001 \\
\hline & $\begin{array}{l}\text { egl-46, } \\
\text { sem-4 }\end{array}$ & Zn finger & & Wu et al., 2001; Toker et al., 2003 \\
\hline & $\begin{array}{l}\text { mec-3, } \\
\text { unc-86 }\end{array}$ & Homeobox & FLP vs. touch neurons & Mitani et al., 1993 \\
\hline & pag-3 & Zn finger & BDU vs. ALM & Jia et al., 1996 \\
\hline & unc-4 & Homeobox & $\begin{array}{l}\text { VA vs. VB motorneurons } \\
\text { DA vs. DB motorneurons }\end{array}$ & $\begin{array}{l}\text { Winnier et al., 1999; } \\
\text { Esmaeili et al., } 2002\end{array}$ \\
\hline & unc-55 & $\begin{array}{l}\text { Nuclear } \\
\text { hormone } \\
\text { receptor }\end{array}$ & DD vs. VD motorneurons & Zhou and Walthall, 1998 \\
\hline & $v a b-7$ & Homeobox & DA vs. DB motorneurons & Esmaeili et al., 2002 \\
\hline
\end{tabular}

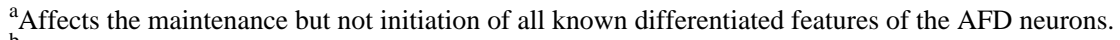

${ }^{\mathrm{b}}$ It is possible that $c e h-10$ affects all known aspects of CAN cell differentiation.

${ }^{\mathrm{c}}$ The switch in VA/VB and DA/DB differentiation programs entails synaptic connectivity, but not all aspects of axon anatomy. 


\subsection{Genetic programs for neuron class specification}

Genes that control neuronal specification have traditionally been identified through forward genetic screens for mutants in which individual neuron classes with easily scorable functions or morphologies (for example motorneurons or sensory neurons) either do not differentiate or function appropriately, resulting, for example, in characteristic sensory defects. The focus on individual neuron classes introduced somewhat of a bias to the types of genes identified. Rather than identifying genes that control early patterning in the nervous system (whose loss would be expected to cause pleiotropic effects), these screens largely identified gene regulatory factors that act at late stages of neuronal development, most often during terminal differentiation of specific subsets of postmitotic neurons (Table 1). The preponderance of transcription factors is consistent with the cell-autonomous programming of cell fate and corroborates early laser ablation experiments (Sulston et al., 1983). A notable exception is the involvement of TGF $\beta$ signaling in determining the terminal identity of ray sensory lineages in males (Lints and Emmons, 1999; Lints et al., 2004).

One theme emerging from the genetic analysis of neuronal specification programs is that there appear to be three separable types of genetic programs operating in a given neuron type (Figure 3A). The well-characterized AIY interneuron class (www.wormatlas.org/neurons.htm/aiy.htm) provides a paradigm for this notion (Figure 3B; Altun-Gultekin et al., 2001; Wenick and Hobert, 2004). One genetic specification program is the induction of pan-neuronal features, which include the expression of many "generic" genes required non-specifically for neuronal function, such as components of the synaptic vesicle machinery. The adoption of pan-neuronal features is genetically separable from a parallel program, the induction of cell-type specific features. Rather than there being many transcription factors, each inducing one subaspect of AIY differentiation, the two homeobox genes ceh-10 and ttx-3 jointly control all known cell-type specific features of AIY, but have little impact on the expression of pan-neuronal features. Third, while ceh-10/ttx-3 control expression of many terminal differentiation genes by directly binding to their cis-regulatory elements, they also induce the expression of intermediary transcription factors that regulate the expression of very specific subfeatures of AIY (Altun-Gultekin et al., 2001; Figure 3B).

Genes that specify other neuronal differentiation programs often fall into one of these types. For example, che-1, ceh-36, unc-30 and mec-3 also affect all neuron-class specific features of the AWE and AWC chemosensory neurons, D-type motorneurons and touch sensory neurons, respectively (Figure 3C and Table 1 for references), while ceh-14 or unc-42, for example, affect only sub-features of the differentiation programs in AFD and command interneurons, respectively (Table 1). A more detailed review of motor neuron specification in C. elegans can be found in Von Stetina et al. (in press).

Based on their anatomical features, ventral cord motor neurons can be divided into specific classes, which are diversified by the action of specific transcription factors. For example, the D-type motor neurons can be subdivided into embryonically and post-embryonically born D-type motor neurons, with distinct muscle innervation properties. The unc-55 nuclear hormone receptor is required to distinguish these two distinct classes. In the absence of unc-55, the VD-class adopts the fate of the DD-class (Zhou and Walthall, 1998). In animals lacking the unc-4 homeobox gene, the postembryonically born A-type motor neurons (VA subclass) adopt aspects of the fate of the B-type neurons (VB subclass; Miller and Niemeyer, 1995; Winnier et al., 1999).

\section{Neuron subclass specification}

Members of the 118 neuron classes defined by White et al. are distinguished by their differential anterior/posterior, dorsal/ventral and left/right position. For example, many head ganglia neuron classes are composed of a pair of two left/right symmetric cells (example: AIY neurons: www.wormatlas.org/ neurons.htm/aiy.htm), while ventral cord motor neuron classes are composed of many longitudinally aligned class members (example: DA1 through DA9 neurons www.wormatlas.org/neurons.htm/DAn.htm). Individual class members can be distinguished by subtle functional criteria (see ASE or AWC examples mentioned below) or by slightly distinct axodendritic projection patterns (for example, DA neuron class members). 
A

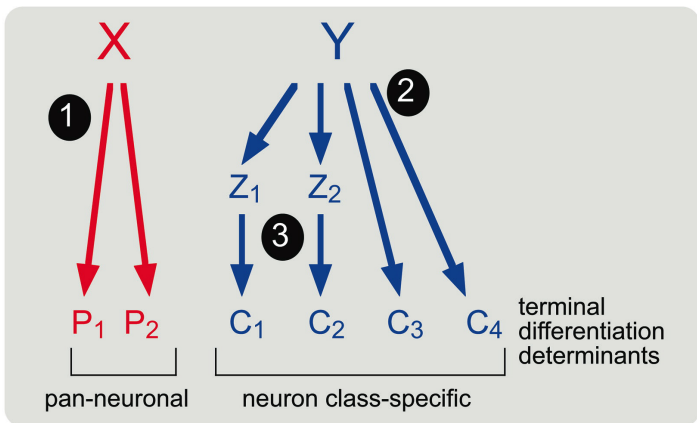

B
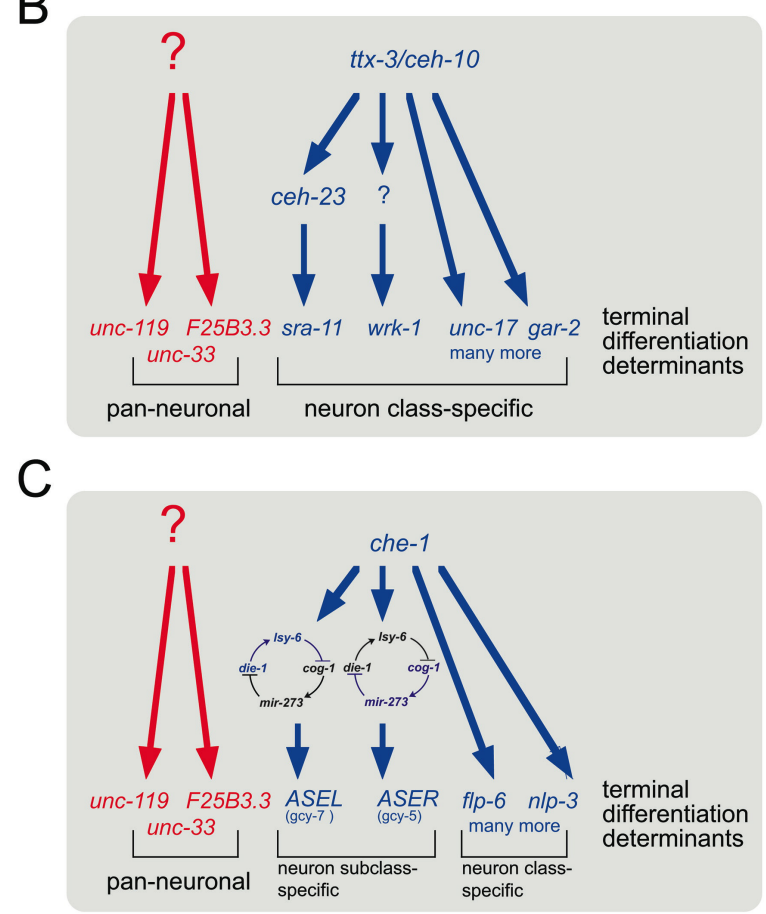

Figure 3.Neuronal specification programs can be divided into genetically distinct steps. (A) " $\mathrm{X}$ " and " $\mathrm{Y}$ " indicate a gene regulatory factor(s) that determine pan-neuronal ("1") versus cell type specific characters ("2", "3"). Factor Y (which should be considered not necessarily as a single factor but a combination of several regulatory factors that form a specific "code") induces neuron-class specific features both directly ("2") and indirectly, via other gene regulatory factors ("3"; factors Z1, Z2, etc.). The principle of a cell-fate determinant acting both directly and indirectly on terminal differentiation markers is a widespread theme. One example is shown in panel B. Other examples include the organ selector gene pha-4 (Gaudet and Mango, 2002), the unc-86 gene (Finney and Ruvkun, 1990; Xue et al., 1993; Duggan et al., 1998) or, in other systems, the eye-selector Pax-6/eyeless (Gehring, 2002). (B,C) Examples and elaborations of the concept shown in panel A. (B) Differentiation of the AIY interneuron class. TTX-3 and CEH-10 proteins bind directly as a heterodimer to the cis-regulatory region of terminal differentiation marker genes such as the genes coding for vesicular neurotransmitter transporters (unc-17), neurotransmitter receptors (gar-2 and others) and scores of other genes identified by genome wide searches (Wenick and Hobert, 2004). TTX-3 and CEH-10 also activate intermediate factors such as CEH-23, which are required for the expression of specific subfeature of the neuron (Altun-Gultekin et al., 2001). The "?" indicates that the wrk-1 gene is expressed in a $t t x-3 / c e h-10$ dependent manner, but contains no $t t x-3 / c e h-10$ binding motif, hence invoking an intermediate transcription factor. (C) Differentiation of the ASE neuron class, composed of ASEL and ASER. Both cells are bilaterally symmetric in terms of morphology and the expression of many terminal differentiation markers (such as flp- 6 or hen-1, as well as many others), yet express distinct chemoreceptors, encoded by the gcy genes. A bistable loop composed of transcription factors and miRNAs (Johnston et al. 2005) drives differentiation into the ASEL state ( $g c y$-7 expression) or the ASER state ( $g c y-5$ expression).

Genetic specification programs that distinguish individual class members are only beginning to be discovered. The RME motorneurons, composed of four radially symmetric cells, RME left, RME right, RME dorsal and RME ventral (www.wormatlas.org/neurons.htm/RME.htm) provide an illuminating example (Huang et al., 2004). Here, the $a h r-1$ transcription factor imposes a RMEL/R "fate" onto an apparent "RMED/V" ground state that is executed by all four neurons. That is, loss of $a h r-1$ causes all four RME neurons to express RMED/V markers, while ectopic expression of $a h r-1$ in all four RME neurons induced RMEL/R fate. A tempting conclusion from this study is that neuron subclasses are diversified from a "neuron class ground state" common to all class members. Notably, the $\mathrm{RMED/V}$ and RMEL/R neurons show little if any lineage relationship. 
Another more recent, and anatomically unexpected subclassification of neuron classes can be observed across the $\mathrm{L} / \mathrm{R}$ axis. Most neuron classes in the nervous system are composed of a pair of two bilaterally symmetric neurons (Sulston, 1983; Hobert et al., 2002). While most known L/R bilateral analogs are indistinguishable from one another based on anatomic, functional and gene expression criteria, the bilaterally symmetric AWC olfactory (www.wormatlas.org/neurons.htm/awc.htm) and ASE gustatory neurons (www.wormatlas.org/neurons.htm/ase.htm) express different spectra of putative chemoreceptors and, therefore, have diverged their chemosensory capacities (Yu et al., 1997; Troemel et al., 1999; Pierce-Shimomura et al., 2001; Wes and Bargmann, 2001). In the case of ASE, this appears to be programmed in an invariant manner into the ASEL and ASER lineages. Diversifying from a "bilaterally symmetric ground state", induced by the che-1 Zn finger transcription factor, a regulatory network of several homeobox genes and microRNAs is required to make ASEL and ASER different from each other (Chang et al., 2003; Johnston and Hobert, 2003; Chang et al., 2004). Interestingly, these factors do not act linearly, but constitute a "bistable feedback loop" (Figure 3C; Johnston et al., 2005). The negative regulatory interaction between individual regulatory factors in this loop ensures that the loop can exist in two states (hence "bistable"). In the ASEL cell, the output of the loop is the induction of a very specific subset of ASEL fate markers, while in the ASER cell, the loop operates with the "opposite" sign, thus causing the induction of the ASER fate. What determines the cell-type specific activity of the loop is currently unknown. Yet this example illustrates that neurons have come up with very sophisticated regulatory devices to ensure their functional diversification. Another notable aspect of ASE cell fate determination is its illustration of the power of forward genetic analysis and the limitation of reverse genetic analysis, the predominant tool of, for example, mouse genetics. Genetic mutant screens for ASE fate determinants have uncovered hypo- and antimorphic alleles of genes whose null phenotype is either absent due to genetic redundancy, or is too pleiotropic. For example, die-1 null mutants die before ASE is generated, while die-1 hypomorphic alleles revealed by genetic screening are viable yet display ASE fate defects (Chang et al., 2004). Similarly, ceh-36 null alleles show no significant ASE cell fate defect, likely due to redundancy with an as yet unknown factor, yet presumptive antimorphic alleles of ceh-36 allowed to implicate the gene in ASE fate determination (Chang et al., 2003; Lanjuin et al., 2003).

Another interesting issue relates to the similarity, rather than difference, of individual neuron class members. 98 neuron classes are composed of pairs of left/right symmetric neurons, which, with the notable exception of the case of ASE and AWC mentioned above, are indistinguishable in terms of all known morphological, functional or gene expression criteria. Yet 35 of these 98 pairs are composed of cells that derive from distinct embryonic lineages (Sulston, 1983). On the one hand, it is tempting to speculate that positional information instructs lineally unrelated neuroblasts to adopt similar, left/right symmetric fates (Schnabel, 1996). On the other hand, the patterned expression of HOX cluster members along the anterior/posterior axis is not determined by absolute positional information, but by intrinsic lineage cues (Cowing and Kenyon, 1996; Wittmann et al., 1997), indicating that positional information can be lineally encoded.

\section{Maintenance and plasticity of neuronal specification}

Many of the transcription factors that determine the differentiated state of a neuron autoregulate their expression and thereby maintain their expression throughout the life of the animal. Although not experimentally tested in any of these cases, this strongly suggests that once a terminally differentiated state is chosen, it is actively maintained by the same factors that initiated the differentiation program. However, a unique feature of the nervous system is its plasticity, that is, its ability to alter specific properties at either defined developmental stages or under changes in external conditions. This has been well documented in the chemosensory system of C. elegans. While the terminally differentiated state of many chemosensory neurons is defined by the expression of specific sets of orphan 7TMRs, their expression profiles can change under defined environmental conditions and upon changes in neuronal activity (Peckol et al., 2001; Nolan et al., 2002; Zhang et al., 2004). TGF $\beta$ signaling plays an important role in the environmental induced alteration of 7TMR expression profiles; TGF $\beta$ signaling is also required to maintain specific 7TMR expression profiles (Nolan et al., 2002). Another prominent example of the plasticity of the worm nervous system is its re-wiring of synaptic connection of a class of ventral cord motorneurons at a specific developmental stage (White et al., 1978). This rewiring process is under control of a ubiquitous developmental timer, the lin-14 gene (Hallam and Jin, 1998). 


\section{Concepts in neuronal fate specification in C. elegans}

\subsection{Combinatorial codes of gene regulatory factors}

Individual cell types are defined by the combinatorial co-expression of terminal differentiation genes ("gene batteries"; Figure 4). Similarly, combinatorial codes of transcription factors control the composition of cell-type specific gene batteries (Davidson, 2001; Hobert, 2004; Lanjuin and Sengupta, 2004). This point is well exemplified by the AIY interneuron class, whose differentiation program is comparatively well defined by scores of terminal differentiation marker genes (Altun-Gultekin et al., 2001; Wenick and Hobert, 2004). Each of the AIY terminal differentiation genes (including neurotransmitter transporters, neurotransmitter receptors, putative adhesion molecules, etc.; Figure 4) is more broadly expressed, but expression of these genes uniquely overlaps in AIY, thereby defining a AIY-specific gene battery. The co-expression of all AIY-class specific genes is lost exclusively in AIY in animals that lack either the $t t x-3$ or the $c e h-10$ homeobox gene. Neither factor alone has the capability to determine AIY interneuron fate, a notion that is derived from the observations that (1) these factors are expressed in more cells than just AIY (ttx-3 is expressed also in AIA, ADL and ASI, ceh-10 in RID and CAN) and (2) that ectopic expression of either of these factors alone does not broadly induce AIY fate. It is rather the unique co-expression in AIY that allows $t t x-3$ and ceh-10 to act together in a complex to directly activate the expression of neuron class-specific genes, through their binding to a motif that is common to most AIY-expressed genes (Wenick and Hobert, 2004). The "combinatorial code" of co-expression of ttx-3 and ceh-10 is however still not a sufficient determinant for AIY fate. Forced co-expression of ttx-3 and ceh-10 in many other neuron classes, causes some but not all neuron classes to execute the AIY differentiation program. The example of $t t x-3$ and $c e h-10$ thus highlights the context-dependency of transcription factor action and, like many other examples, seriously questions the concept of single "master regulators" of cell fate determination. That is, rather than there being a single master-regulator, it is the unique combination of gene regulatory factors present in a given neuron class that determines its fate (Davidson, 2001; Hobert, 2004; Lanjuin and Sengupta, 2004; Lints et al., 2004).

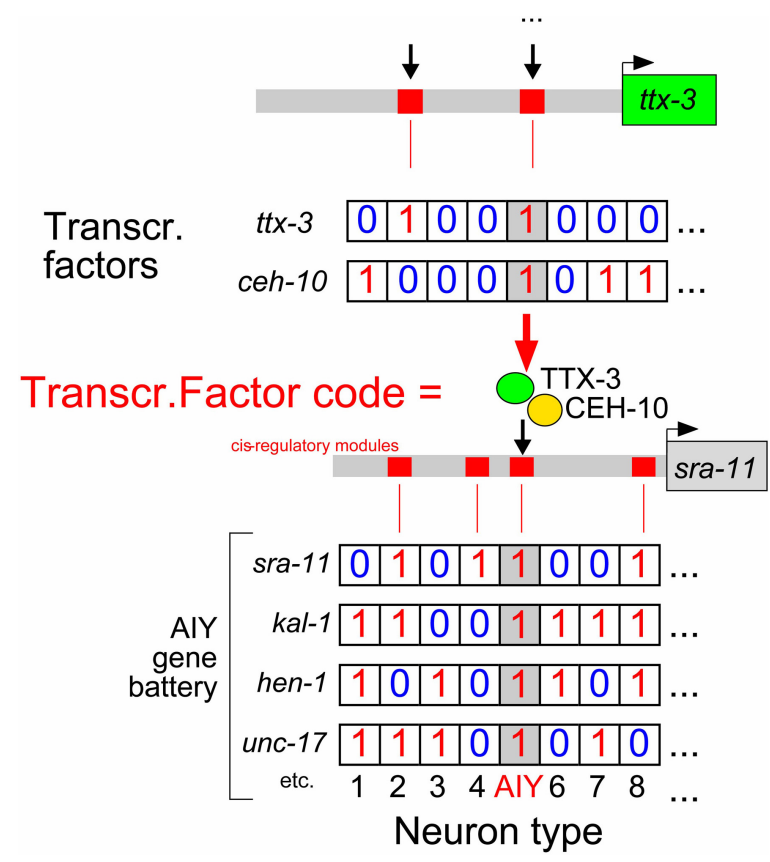

Figure 4. Combinatorial gene expression patterns determine cell fates. This schematic diagram illustrates three principles. First, individual neuron types (here: AIY) are defined not by the expression of unique terminal differentiation genes, but by the expression of a unique combination of more broadly expressed genes (here: sra-11, hen-1, kal-1 and unc-17; Altun-Gultekin et al., 2001). Second, the co-expression of terminal differentiation markers is regulated by cis-regulatory control elements (here illustrated for the sra-11 gene) that are occupied in a cell-type specific manner and combinatorial sets of co-expressed transcription factors (Wenick and Hobert, 2004). Third, the combinatorial co-expression of gene regulatory factors is again brought about by specific cis-regulatory elements that control the expression of these regulatory factors. Cell type specification therefore involves hierarchical levels of combinatorial codes of co-expressed genes. Note that for simplicity, the gene regulatory events shown here are based on transcriptional activation. Figure 5 illustrates that apparent activation could in fact be due to sequential repression. " 1 " indicates expression of a gene, "0" indicates no expression. The binary behavior of gene expression is an oversimplification since intermediary levels of gene expression can also be instructive, but it is nevertheless a useful concept if one takes " 1 " to mean that the level of gene expression is sufficient to confer a specific property to a cell and " 0 " to mean insufficient levels of gene expression. 
Consistent with the concept of combinatorial interaction of gene regulatory factors, the coupling of gene regulatory factors to specific effector outputs is not conserved in individual cell types. For example, the lim- 6 homeobox gene regulates the expression of the GABA synthesizing enzyme unc-25 and the glutamate receptor $g l r-1$ in the RIS interneuron, but, although expressed in the RME motorneurons, it does not regulate the expression of either gene in this cell type (Tsalik et al., 2003). Other examples are the $t t x-3$ and ceh-23 homeobox genes whose expression overlaps in both AIY and ADL; ttx-3 regulates ceh-23 in AIY, but not in ADL (Altun-Gultekin et al., 2001). From the perspective of terminal differentiation genes (e.g., unc-25, glr-1), one can therefore conclude that rather than being under control of a common regulatory factor in different cell types, they are under control of cell-type specific combinations of gene regulatory factors.

The principle of combinatorial coding also rationalizes the effect that a loss of a cell-fate determinant has on neuronal cell fate. In some cases, loss of the determinant (e.g. che-1 or ttx-3; Figure 3B, C) causes a loss of overall identity of a neuron, while in other cases (e.g. unc-4, unc-130, cfi-1; Table 1) an alternative fate is adopted. These differential effects may reflect the information content of specific gene regulatory codes. For example, assume that transcription factor $\mathrm{X}$ regulates aspects of terminal differentiation but also represses transcription factor $\mathrm{V}$. Moreover, assume that the transcription factors $\mathrm{X}, \mathrm{Y}, \mathrm{Z}$ determines fate "A" and the code $\mathrm{V}, \mathrm{Y}, \mathrm{Z}$ determines fate "B". Loss of the factor $\mathrm{X}$ leads to a transformation from "A" fate (defined by XYZ) to "B" (VYZ) since the "left-over" code still carries instructive information. If the code left after removal of one transcription factors (e.g. remove factor Z) does not specify any cell type, the neuron may remain undifferentiated.

The combinatorial coding by co-expression of defined transcription factors relays the problem of neuronal fate specification to more "upstream" levels. In the case of AIY, an upstream code of co-expressed transcription factors likely determines co-expression of $c e h-10$ and $t t x-3$ specifically in AIY. Neuronal fate specification can therefore be considered as the interpretation of multiple, hierarchical layers of transcription factor codes (Figure 4). An individual transcription factor can be a part of a code at different levels; for example, unc- 86 works at different stages in the development of neuroblast lineage and presumably interacts with distinct sets of factors at different stages (Finney and Ruvkun, 1990; Duggan et al., 1998; Sze et al., 2002), so does the lin-32 bHLH gene (Portman and Emmons, 2000). It is in these hierarchical layers of transcription factor codes where one could see how cell lineage and history are coupled to terminal neuronal fates. At each developmental stage (Figure 1), an individual neuroblast contains a specific and unique combination of transcription factors which are required to select the next level of transcription factor code. Lineage-specific transcription factor codes may be brought about by a lineage-intrinsic coordinate system. This coordinate system could be determined by a combination of early blastomere induction events and the ensuing differential anterior/posterior segregation of cell fate determinants into only one daughter cells after a cell division, demonstrated to occur for the POP-1 transcription factor (Lin et al., 1998). HAM-1, a novel protein with no obvious homologs, also appears to have a role in determining the asymmetric fate of the daughters of a neuroblast cell division (Guenther and Garriga, 1996). Another component of this coordinate system may be the temporally controlled induction of transcription factors in analogy to what has been observed in fly neuroblast determination (Pearson and Doe, 2004). A necessity to time transcription factor activity precisely has recently been demonstrated during cell fate determination in the AWA sensory neuron class. To make this neuron class different from its sister neuron AWG, a brief pulse of expression of the lin-11 homeobox is required; forced prolonged expression of lin-11 disrupts AWA cell fate (Sarafi-Reinach et al., 2001).

The concept of combinatorial coding of gene regulatory factors is not limited to transcriptional regulation but includes a class of small regulatory factors, microRNAs. miRNAs are small RNA molecules that bind to complementary sequences in the 3'UTR of target genes and prevent their translation (Bartel, 2004). Originally identified as regulators of developmental timing of non-neuronal cell division patterns (Lee et al., 1993; Reinhart et al., 2000), recent genetic and reverse genetic studies have shown that miRNAs play a role in neuronal specification as well. Specifically, the two miRNAs $l s y-6$ and mir-273 are involved in diversifying the fates of a two members of a class of bilaterally symmetric sensory neurons, the ASE neurons (Johnston and Hobert, 2003; Chang et al., 2004; Figure 3C). Animal genomes contain an abundance of miRNA genes, the vast majority of which are uncharacterized. Expression pattern analysis in C. elegans reveals neuron-class specific expression profiles of many miRNAs (Penney, E. B. and O.H., unpubl. data). Together with the $l s y-6$ and mir-273 data, one can expect that miRNAs fulfill widespread roles in neuronal specification. As clearly demonstrated in the case of the ASE neurons, miRNAs can work much like transcription factors as necessary and sufficient switches to trigger cellular specification programs. In analogy to transcription factor codes, combinatorial codes of miRNAs within a given cell-type may similarly contribute to cellular differentiation, also by acting through differentially occupied cis-regulatory elements which are in the case of miRNAs located in 3'UTRs (for a more in-depth discussion of the conceptual similarity of transcription factors and miRNAs, see Hobert, 2004). 


\subsection{Repressing alternative or default programs and sequential repression}

The importance of repression of alternative or default programs has long been recognized in a variety of contexts (Figure 5). Two classic examples operate in motorneurons and touch neurons. In the absence of the unc-4 homeobox gene, the VA motorneurons execute many but not all of the fates normally characteristic for the VB motorneuron fate (Miller and Niemeyer, 1995; Winnier et al., 1999). unc-4 therefore prevents VB cell fate to be expressed in the VA neurons. unc-4 exerts its repressive activity in conjunction with the transcriptional co-repressor unc-37/Groucho (Miller et al., 1993; Pflugrad et al., 1997). The unc-86 and mec-3 homeobox genes have the capacity to combinatorially drive touch neuron fate in several cell types, but are prevented from doing so in a subset of these cells, such as the FLP cells, where unc-86/mec-3 activity is genetically masked by the egl-44 and egl-46 genes (Mitani et al., 1993). Other examples are listed in Table 1. One of these examples warrants specific attention since it illustrates both concepts of repression of defaults states and combinatorial transcription factor codes. The HOX cluster gene egl-5 imposes specific male sensory ray neuronal identities (ray 3-5) on a common ground state (normally executed only by ray 2). It does so either alone in ray 3 (or with an unknown co-factor), together with the HOX cluster gene $m a b-5$ (in ray 4), the Pax gene $m a b-18$ (in ray 5) or a SMAD-type TGF $\beta$ effector (in ray 6; Lints et al., 2004).

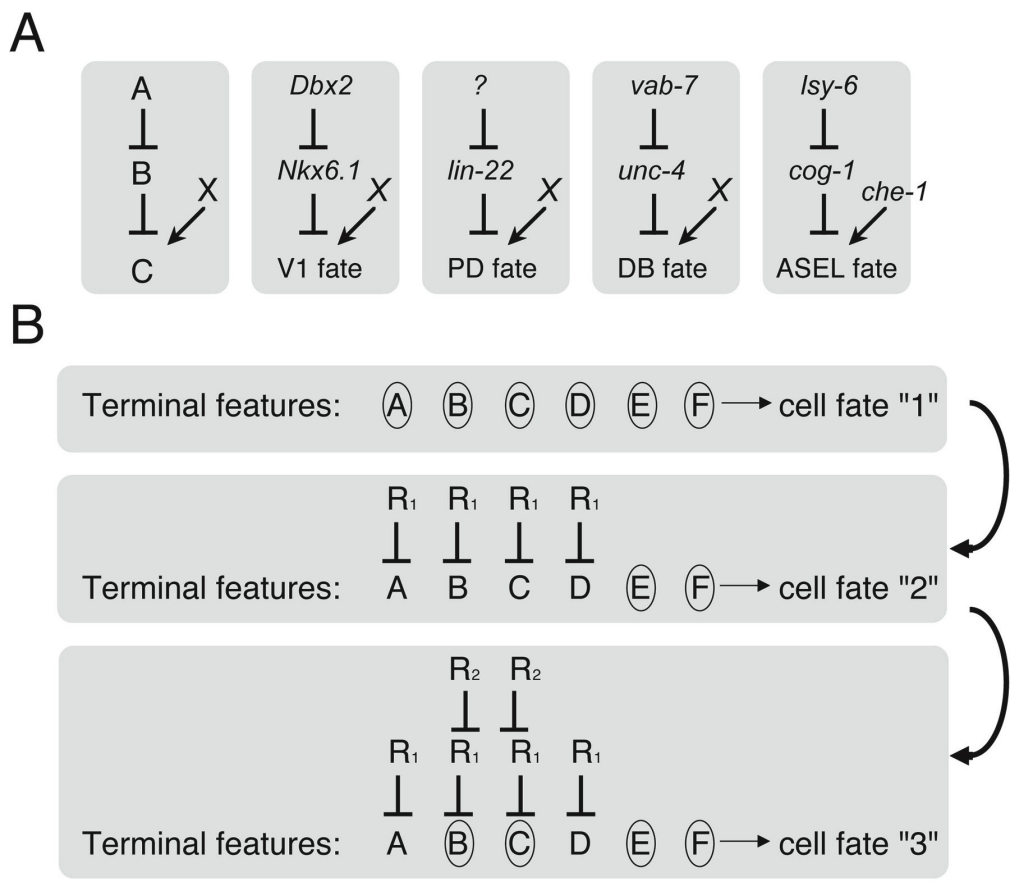

Figure 5. Sequential repression of neuronal fates. (A) Cascades of sequentially acting negative regulatory factors induce specific cell fates. Left panel: The presence of "A" in a given cell type induces a given cell fate, exemplified by gene "C" through repression of factor B, which is a repressor of C. A selected set of examples in which this scheme has been found to apply, namely in ventral cord motorneurons in vertebrates (V1 motorneurons; Muhr et al., 2001) and worms DB-type motorneurons (Esmaeili et al., 2002), worm chemosensory neurons (ASEL neuron; Chang et al., 2003) and worm postdeirid neurons ("PD fate") formed from the V5 ectoblasts are shown. In the case of the DB motorneurons, the VAB-7 protein not only inhibits the $u n c-4$ gene, but also positively regulates DB fate (X=vab-7). In the case of the ASE neurons, latent transcriptional activation is conferred by the CHE- $1 \mathrm{Zn}$ finger protein $(\mathrm{X}=$ che-1). Its activity is sequentially repressed and de-repressed by cog-1, lim-6 and other repressors (Chang et al., 2003; Chang et al., 2004). (B) Evolvability of gene expression profiles based on sequential repression. An ontogenetic and/or phylogenetic ground state is defined by the expression of set of characters (circles indicate the expression of the character). During development and/or evolution (indicated by arrows), sequential repression can create diverse cell fates, which are defined by the cell-type specific combinatorial expression of a subset of the characters.

The concept of cell fate induction by repressing a default state has been significantly expanded to include several layers of sequential repressive interactions, thus making cell fate induction a "de-repression" phenomenon. This is well illustrated in the vertebrate spinal cord (Muhr et al., 2001) but also in several cases in the C. elegans nervous system. One first glimpse in this direction came from the lin-22 gene. In lin-22 mutants, several hypodermal cell lineages, derived from the V1,V2, V3, V4, and V6 ectoblasts, inappropriately adopt neuronal character (Figure 2; Horvitz et al., 1983). Thus, lin-22 serves to repress neuronal fate in these lineages. However, the V5 cell normally executes the neuronal differentiation program that is executed inappropriately in V1, V2, V3, V4 and V6 in lin-22 mutants. Therefore, the inhibitory activity of lin-22 on neuronal fate is repressed in V5 (Figure 2). The overall scheme emerging from this analysis is that a specific fate is not necessarily induced by a positive inducer, but by sequential de-repression of a common ground state, as illustrated in Figure 5. This scheme is not only emerging in 
the vertebrate spinal cord, but is also apparent in the fly nervous system as well as in other instances of the worm nervous system. For example, the vab-7 homeobox gene induces DB fate by repressing the expression of the unc-4 homeobox gene, which represses DB fate specification (Esmaeili et al., 2002). In the ASEL sensory neuron, the lsy-6 miRNA represses the expression of the $\operatorname{cog}-1$ homeobox gene, a repressor of ASEL fate (Chang et al., 2003; Johnston et al., 2003). In many cases described above (vertebrate spinal cord, DB fate, ASE fate), a critical and evolutionarly ancient component of the repressive interactions is the Groucho co-repressor protein (Pflugrad et al., 1997; Muhr et al., 2001; Chang et al., 2003). Figure 5B illustrates how sequential repression could contribute to the potential evolvability of gene expression profiles, an important feature for an organ that needs to maintain a set of commonly expressed genes (pan-neuronal genes) but needs to "invent" novel gene expression profiles in order to generate neuronal diversity.

\section{Perspectives}

Terminal neuronal differentiation programs have been revealed in several cases on a single neuron basis, therefore fulfilling the promises of C. elegans as a model system. However, much remains to be learned in regard to the mechanisms of lineage programming, particularly in the less accessible mid-embryonic stages. With the abundance of cell-type specific $g f p$ markers and the SNP-based facilitation of traditional mapping and cloning approaches, it will be possible to now perform much larger scale screens for neuronal fate mutants. As the examples mentioned above illustrate, the key to success will be the ease with which specific phenotypes can be screened for. Rather than using terminal differentiation marker, which bias for the retrieval of genes involved in terminal differentiation, it is important to move to $g f p$ markers that label earlier lineage decisions and to use a four-dimensional video microscopy system (Schnabel et al., 1997) to assist precise phenotypic scoring of lineage defects. Genome wide analysis of expression patterns of gene regulatory factors such as transcription factors and miRNAs, if done with single cell resolution and at embryonic stages, will also provide testable hypotheses about the existence of "codes" that are characteristic for individual lineages and will open the door to a reverse genetic analysis of these codes.

\section{Acknowledgments}

Work in the author's laboratory is funded by the HHMI, NIH, the McKnight Foundation and Irma T. Hirschl Trust. I am indebted to many colleagues for ongoing discussions and comments on the manuscript, particularly David Miller, and apologize to all colleagues whose work could not be appropriately discussed due to space constraints.

\section{References}

Altun-Gultekin, Z., Andachi, Y., Tsalik, E.L., Pilgrim, D., Kohara, Y., and Hobert, O. (2001). A regulatory cascade of three homeobox genes, ceh-10,ttx-3 and ceh-23, controls cell fate specification of a defined interneuron class in C. elegans. Development 128, 1951-1969. Abstract

Aspock, G., Ruvkun, G., and Burglin, T.R. (2003). The Caenorhabditis elegans ems class homeobox gene ceh-2 is required for M3 pharynx motoneuron function. Development 130, 3369-3378. Article

Baran, R., Aronoff, R., and Garriga, G. (1999). The C. elegans homeodomain gene unc-42 regulates chemosensory and glutamate receptor expression. Development 126, 2241-2251.

Bartel, D.P. (2004). MicroRNAs. Genomics, biogenesis, mechanism, and function. Cell 116, 281-297. Abstract Article

Baum, P.D., Guenther, C., Frank, C.A., Pham, B.V., and Garriga, G. (1999). The Caenorhabditis elegans gene ham-2 links Hox patterning to migration of the HSN motor neuron. Genes Dev. 13, 472-483.

Brockie, P.J., Madsen, D.M., Zheng, Y., Mellem, J., and Maricq, A.V. (2001). Differential expression of glutamate receptor subunits in the nervous system of Caenorhabditis elegans and their regulation by the homeodomain protein UNC-42. J. Neurosci. 21, 1510-1522.

Cameron, S., Clark, S.G., McDermott, J.B., Aamodt, E., and Horvitz, H.R. (2002). PAG-3, a Zn-finger transcription factor, determines neuroblast fate in C. elegans. Development 129, 1763-1774. Abstract 
Cassata, G., Kagoshima, H., Andachi, Y., Kohara, Y., Durrenberger, M.B., Hall, D.H., and Burglin, T.R. (2000). The LIM homeobox gene ceh-14 confers thermosensory function to the AFD neurons in Caenorhabditis elegans. Neuron 25, 587-597. Article

Chalfie, M., Horvitz, H.R., and Sulston, J.E. (1981). Mutations that lead to reiterations in the cell lineages of $C$. elegans. Cell 24, 59-69. Article

Chalfie, M., and Sulston, J. (1981). Developmental genetics of the mechanosensory neurons of Caenorhabditis elegans. Dev. Biol. 82, 358-370. Abstract Article

Chang, S., Johnston, R.J., Frokjaer-Jensen, C., Lockery, S., and Hobert, O. (2004). MicroRNAs act sequentially and asymmetrically to control chemosensory laterality in the nematode. Nature 430, 785-789. Abstract Article

Chang, S., Johnston, R.J., Jr., and Hobert, O. (2003). A transcriptional regulatory cascade that controls left/right asymmetry in chemosensory neurons of C. elegans. Genes Dev. 17, 2123-2137. Abstract Article

Clark, S.G., Chisholm, A.D., and Horvitz, H.R. (1993). Control of cell fates in the central body region of C. elegans by the homeobox gene lin-39. Cell 74, 43-55. Article

Clark, S.G., and Chiu, C. (2003). C. elegans ZAG-1, a Zn-finger-homeodomain protein, regulates axonal development and neuronal differentiation. Development 130, 3781-3794. Article

Cowing, D., and Kenyon, C. (1996). Correct Hox gene expression established independently of position in Caenorhabditis elegans. Nature 382, 353-356. Abstract Article

Davidson, E.H. (2001). Genomic Regulatory Systems (San Diego: Academic Press).

Desai, C., Garriga, G., McIntire, S.L., and Horvitz, H.R. (1988). A genetic pathway for the development of the Caenorhabditis elegans HSN motor neurons. Nature 336, 638-646. Article

Duggan, A., Ma, C., and Chalfie, M. (1998). Regulation of touch receptor differentiation by the Caenorhabditis elegans mec-3 and unc-86 genes. Development 125, 4107-4119. Abstract

Eastman, C., Horvitz, H.R., and Jin, Y. (1999). Coordinated transcriptional regulation of the unc-25 glutamic acid decarboxylase and the unc-47 GABA vesicular transporter by the Caenorhabditis elegans UNC-30 homeodomain protein. J. Neurosci. 19, 6225-6234. Abstract

Esmaeili, B., Ross, J.M., Neades, C., Miller, D.M., III., and Ahringer, J. (2002). The C. elegans even-skipped homologue, $v a b-7$, specifies DB motoneurone identity and axon trajectory. Development 129, 853-862. Abstract

Finney, M., and Ruvkun, G. (1990). The unc-86 gene product couples cell lineage and cell identity in C. elegans. Cell 63, 895-905. Abstract Article

Finney, M., Ruvkun, G., and Horvitz, H.R. (1988). The C. elegans cell lineage and differentiation gene unc-86 encodes a protein with a homeodomain and extended similarity to transcription factors. Cell 55, 757-769. Article

Forrester, W.C., Perens, E., Zallen, J.A., and Garriga, G. (1998). Identification of Caenorhabditis elegans genes required for neuronal differentiation and migration. Genetics 148, 151-165.

Gaudet, J., and Mango, S.E. (2002). Regulation of organogenesis by the Caenorhabditis elegans FoxA protein PHA-4. Science 295, 821-825. Article

Gehring, W.J. (2002). The genetic control of eye development and its implications for the evolution of the various eye-types. Int. J. Dev. Biol. 46, 65-73.

Guenther, C., and Garriga, G. (1996). Asymmetric distribution of the C. elegans HAM-1 protein in neuroblasts enables daughter cells to adopt distinct fates. Development 122, 3509-3518. Abstract 
Hallam, S., Singer, E., Waring, D., and Jin, Y. (2000). The C. elegans NeuroD homolog cnd-1 functions in multiple aspects of motor neuron fate specification. Development 127, 4239-4252. Abstract

Hallam, S.J., and Jin, Y. (1998). lin-14 regulates the timing of synaptic remodelling in Caenorhabditis elegans. Nature 395, 78-82. Abstract Article

Hemmati-Brivanlou, A., and Melton, D. (1997). Vertebrate neural induction. Annu. Rev. Neurosci. 20 , 43-60. Abstract Article

Hobert, O. (2004). Common logic of transcription factor and microRNA action. Trends Biochem Sci. 29, $462-468$. Abstract Article

Hobert, O., D'Alberti, T., Liu, Y., and Ruvkun, G. (1998). Control of neural development and function in a thermoregulatory network by the LIM homeobox gene lin-11. J. Neurosci. 18, 2084-2096.

Hobert, O., Johnston, R.J., Jr., and Chang, S. (2002). Left-right asymmetry in the nervous system: the Caenorhabditis elegans model. Nat. Rev. Neurosci 3, 629-640. Abstract Article

Hobert, O., Mori, I., Yamashita, Y., Honda, H., Ohshima, Y., Liu, Y., and Ruvkun, G. (1997). Regulation of interneuron function in the $C$. elegans thermoregulatory pathway by the $t$ tx-3 LIM homeobox gene. Neuron 19 , 345-357. Article

Hobert, O., Tessmar, K., and Ruvkun, G. (1999). The Caenorhabditis elegans lim-6 LIM homeobox gene regulates neurite outgrowth and function of particular GABAergic neurons. Development 126, 1547-1562. Abstract

Horvitz, H.R., Sternberg, P.W., Greenwald, I.S., Fixsen, W., and Ellis, H.M. (1983). Mutations that affect neural cell lineages and cell fates during the development of the nematode Caenorhabditis elegans. Cold Spring Harb Symp. Quant. Biol. 48 (Pt 2), 453-463. Abstract

Huang, X., Powell-Coffman, J.A., and Jin, Y. (2004). The AHR-1 aryl hydrocarbon receptor and its co-factor the AHA-1 aryl hydrocarbon receptor nuclear translocator specify GABAergic neuron cell fate in $C$. elegans. Development 131, 819-828. Abstract Article

Hutter, H. (2003). Extracellular cues and pioneers act together to guide axons in the ventral cord of C. elegans. Development.

Hutter, H., and Schnabel, R. (1994). glp-1 and inductions establishing embryonic axes in C. elegans. Development 120, 2051-2064. Abstract

Jia, Y., Xie, G., and Aamodt, E. (1996). pag-3, a Caenorhabditis elegans gene involved in touch neuron gene expression and coordinated movement. Genetics 142, 141-147.

Jin, Y., Hoskins, R., and Horvitz, H.R. (1994). Control of type-D GABAergic neuron differentiation by $C$. elegans UNC-30 homeodomain protein. Nature 372, 780-783. Abstract Article

Johnston, R.J., Chang, S., Etchberger, J.F., Ortiz, C.O., and Hobert, O. (2005). MicroRNAs acting in a double-negative feedback loop to control a neuronal cell fate decision. Proc. Natl. Acad. Sci. USA 102, 12449-12454. Abstract Article

Johnston, R.J., and Hobert, O. (2003). A microRNA controlling left/right neuronal asymmetry in Caenorhabditis elegans. Nature 426, 845-849. Abstract Article

Kenyon, C. (1986). A gene involved in the development of the posterior body region of C. elegans. Cell 46, 477-487. Article

Koga, M., and Ohshima, Y. (2004). The C. elegans ceh-36 gene encodes a putative homeodomain transcription factor involved in chemosensory functions of ASE and AWC neurons. J. Mol. Biol. 336, 579-587. Article 
Labouesse, M., Sookhareea, S., and Horvitz, H.R. (1994). The Caenorhabditis elegans gene lin-26 is required to specify the fates of hypodermal cells and encodes a presumptive zinc-finger transcription factor. Development 120 , 2359-2368. Abstract

Lanjuin, A., and Sengupta, P. (2004). Specification of chemosensory neuron subtype identities in Caenorhabditis elegans. Curr. Opin. Neurobiol. 14, 22-30. Abstract Article

Lanjuin, A., VanHoven, M.K., Bargmann, C.I., Thompson, J.K., and Sengupta, P. (2003). Otx/otd homeobox genes specify distinct sensory neuron identities in C. elegans. Dev. Cell 5, 621-633. Abstract Article

Lee, R.C., Feinbaum, R.L., and Ambros, V. (1993). The C. elegans heterochronic gene lin-4 encodes small RNAs with antisense complementarity to lin-14. Cell 75, 843-854. Abstract Article

Lin, R., Hill, R.J., and Priess, J.R. (1998). POP-1 and anterior-posterior fate decisions in C. elegans embryos. Cell 92, 229-239. Abstract Article

Lints, R., and Emmons, S.W. (1999). Patterning of dopaminergic neurotransmitter identity among Caenorhabditis elegans ray sensory neurons by a TGF $\beta$ family signaling pathway and a Hox gene. Development 126, 5819-5831. Abstract

Lints, R., Jia, L., Kim, K., Li, C., and Emmons, S.W. (2004). Axial patterning of C. elegans male sensilla identities by selector genes. Dev. Biol. 269, 137-151. Abstract Article

Melkman, T., and Sengupta, P. (2004). The worm's sense of smell. Development of functional diversity in the chemosensory system of Caenorhabditis elegans. Dev. Biol. 265, 302-319. Abstract Article

Miller, D.M., III, and Niemeyer, C.J. (1995). Expression of the unc-4 homeoprotein in Caenorhabditis elegans motor neurons specifies presynaptic input. Development 121, 2877-2886. Abstract

Miller, D.M. III, Niemeyer, C.J., and Chitkara, P. (1993). Dominant unc-37 mutations suppress the movement defect of a homeodomain mutation in unc-4, a neural specificity gene in Caenorhabditis elegans. Genetics 135, 741-753. Abstract

Mitani, S., Du, H., Hall, D.H., Driscoll, M., and Chalfie, M. (1993). Combinatorial control of touch receptor neuron expression in Caenorhabditis elegans. Development 119, 773-783. Abstract

Modolell, J. (1997). Patterning of the adult peripheral nervous system of Drosophila. Perspect Dev. Neurobiol. 4, 285-296. Abstract

Much, J.W., Slade, D.J., Klampert, K., Garriga, G., and Wightman, B. (2000). The fax-1 nuclear hormone receptor regulates axon pathfinding and neurotransmitter expression. Development 127, 703-712.

Muhr, J., Andersson, E., Persson, M., Jessell, T.M., and Ericson, J. (2001). Groucho-mediated transcriptional repression establishes progenitor cell pattern and neuronal fate in the ventral neural tube. Cell 104, 861-873. Abstract Article

Nolan, K.M., Sarafi-Reinach, T.R., Horne, J.G., Saffer, A.M., and Sengupta, P. (2002). The DAF-7 TGF- $\beta$ signaling pathway regulates chemosensory receptor gene expression in C. elegans. Genes Dev. 16, 3061-3073. Abstract Article

Pearson, B.J., and Doe, C.Q. (2004). Specification of temporal identity in the developing nervous system. Annu. Rev. Cell Dev. Biol. 20, 619-647. Abstract Article

Peckol, E.L., Troemel, E.R., and Bargmann, C.I. (2001). Sensory experience and sensory activity regulate chemosensory receptor gene expression in Caenorhabditis elegans. Proc. Natl. Acad. Sci. USA 98, 11032-11038. Abstract Article 
Pflugrad, A., Meir, J.Y., Barnes, T.M., and Miller, D.M., III. (1997). The Groucho-like transcription factor UNC-37 functions with the neural specificity gene unc-4 to govern motor neuron identity in C. elegans. Development 124 , 1699-1709. Abstract

Pierce-Shimomura, J.T., Faumont, S., Gaston, M.R., Pearson, B.J., and Lockery, S.R. (2001). The homeobox gene lim-6 is required for distinct chemosensory representations in C. elegans. Nature 410, 694-698. Abstract Article

Portman, D.S., and Emmons, S.W. (2000). The basic helix-loop-helix transcription factors LIN-32 and HLH-2 function together in multiple steps of a C. elegans neuronal sublineage. Development 127, 5415-5426. Abstract

Prasad, B.C., Ye, B., Zackhary, R., Schrader, K., Seydoux, G., and Reed, R.R. (1998). unc-3, a gene required for axonal guidance in Caenorhabditis elegans, encodes a member of the $\mathrm{O} / \mathrm{E}$ family of transcription factors. Development 125, 1561-1568. Abstract

Pujol, N., Torregrossa, P., Ewbank, J.J., and Brunet, J.F. (2000). The homeodomain protein CePHOX2/CEH-17 controls antero-posterior axonal growth in C. elegans. Development 127, 3361-3371.

Reinhart, B.J., Slack, F.J., Basson, M., Pasquinelli, A.E., Bettinger, J.C., Rougvie, A.E., Horvitz, H.R., and Ruvkun, G. (2000). The 21-nucleotide let-7 RNA regulates developmental timing in Caenorhabditis elegans. Nature 403, 901-906. Abstract Article

Ruvkun, G. (1997). Patterning the nervous system. In C.elegans II, D.L. Riddle, T. Blumenthal, B.J. Meyer, and J.R. Priess, eds. (Cold Spring Harbor, N.Y.: Cold Spring Harbor Laboratory Press), pp. 543-582.

Sagasti, A., Hobert, O., Troemel, E.R., Ruvkun, G., and Bargmann, C.I. (1999). Alternative olfactory neuron fates are specified by the LIM homeobox gene lim-4. Genes Dev. 13, 1794-1806.

Sarafi-Reinach, T.R., Melkman, T., Hobert, O., and Sengupta, P. (2001). The lin-11 LIM homeobox gene specifies olfactory and chemosensory neuron fates in C. elegans. Development 128, 3269-3281. Abstract

Sarafi-Reinach, T.R., and Sengupta, P. (2000). The forkhead domain gene unc-130 generates chemosensory neuron diversity in C. elegans. Genes Dev. 14, 2472-2485. Article

Satterlee, J.S., Sasakura, H., Kuhara, A., Berkeley, M., Mori, I., and Sengupta, P. (2001). Specification of thermosensory neuron fate in $C$. elegans requires $t$ tx-1, a homolog of otd/Otx. Neuron 31, 943-956. Article

Schnabel, R. (1996). Pattern formation: regional specification in the early C. elegans embryo. Bioessays 18 , 591-594. Abstract Article

Schnabel, R., Hutter, H., Moerman, D., and Schnabel, H. (1997). Assessing normal embryogenesis in Caenorhabditis elegans using a 4D microscope: variability of development and regional specification. Dev. Biol. 184, 234-265. Abstract Article

Sengupta, P., Colbert, H.A., and Bargmann, C.I. (1994). The C. elegans gene odr-7 encodes an olfactory-specific member of the nuclear receptor superfamily. Cell 79, 971-980. Article

Shaham, S., and Bargmann, C.I. (2002). Control of neuronal subtype identity by the C. elegans ARID protein CFI-1. Genes Dev. 16, 972-983. Article

Shi, Y., and Mello, C. (1998). A CBP/p300 homolog specifies multiple differentiation pathways in Caenorhabditis elegans. Genes Dev. 12, 943-955. Abstract

Sulston, J.E. (1983). Neuronal cell lineages in the nematode Caenorhabditis elegans. Cold Spring Harb. Symp. Quant. Biol. 48, 443-452. Abstract

Sulston, J.E., Schierenberg, E., White, J.G., and Thomson, J.N. (1983). The embryonic cell lineage of the nematode Caenorhabditis elegans. Dev. Biol. 100, 64-119. Abstract Article 
Swoboda, P., Adler, H.T., and Thomas, J.H. (2000). The RFX-type transcription factor DAF-19 regulates sensory neuron cilium formation in C. elegans. Mol. Cell 5, 411-421. Abstract Article

Sze, J.Y., Zhang, S., Li, J., and Ruvkun, G. (2002). The C. elegans POU-domain transcription factor UNC-86 regulates the tph-1 tryptophan hydroxylase gene and neurite outgrowth in specific serotonergic neurons. Development 129, 3901-3911. Abstract

Toker, A.S., Teng, Y., Ferreira, H.B., Emmons, S.W., and Chalfie, M. (2003). The Caenorhabditis elegans spalt-like gene sem-4 restricts touch cell fate by repressing the selector Hox gene egl-5 and the effector gene mec-3. Development 130, 3831-3840. Article

Troemel, E.R., Sagasti, A., and Bargmann, C.I. (1999). Lateral signaling mediated by axon contact and calcium entry regulates asymmetric odorant receptor expression in C. elegans. Cell 99, 387-398. Abstract Article

Tsalik, E.L., Niacaris, T., Wenick, A.S., Pau, K., Avery, L., and Hobert, O. (2003). LIM homeobox gene-dependent expression of biogenic amine receptors in restricted regions of the C. elegans nervous system. Dev. Biol. 263, 81-102. Abstract Article

Uchida, O., Nakano, H., Koga, M., and Ohshima, Y. (2003). The C. elegans che-1 gene encodes a zinc finger transcription factor required for specification of the ASE chemosensory neurons. Development 130, $1215-1224$. Article

Von Stetina, S., Treinin, M., and Miller, D. (in press). The Motor Circuit. In: the Neurobiology of C. elegans, IRN Vol. 69 (London: Elsevier)

Wacker, I., Schwarz, V., Hedgecock, E.M., and Hutter, H. (2003). zag-1, a Zn-finger homeodomain transcription factor controlling neuronal differentiation and axon outgrowth in C. elegans. Development 130, 3795-3805. Article

Way, J.C., and Chalfie, M. (1988). mec-3, a homeobox-containing gene that specifies differentiation of the touch receptor neurons in C. elegans. Cell 54, 5-16. Article

Wenick, A.S., and Hobert, O. (2004). Genomic cis-regulatory architecture and trans-acting regulators of a single interneuron-specific gene battery in C. elegans. Dev. Cell 6, 757-770. Abstract Article

Wes, P.D., and Bargmann, C.I. (2001). C. elegans odour discrimination requires asymmetric diversity in olfactory neurons. Nature 410, 698-701. Abstract Article

White, J.G., Albertson, D.G., and Anness, M.A. (1978). Connectivity changes in a class of motoneurons during the development of a nematode. Nature 271, 764-766. Article

White, J.G., Southgate, E., Thomson, J.N., and Brenner, S. (1986). The structure of the nervous system of the nematode Caenorhabditis elegans. Philos. Trans. R. Soc. Lond., B, Biol. Sci. 314, 1-340.

Winnier, A.R., Meir, J.Y., Ross, J.M., Tavernarakis, N., Driscoll, M., Ishihara, T., Katsura, I., and Miller, D.M., III (1999). UNC-4/UNC-37-dependent repression of motor neuron-specific genes controls synaptic choice in Caenorhabditis elegans. Genes Dev. 13, 2774-2786. Abstract Article

Wittmann, C., Bossinger, O., Goldstein, B., Fleischmann, M., Kohler, R., Brunschwig, K., Tobler, H., and Muller, F. (1997). The expression of the C. elegans labial-like Hox gene ceh-13 during early embryogenesis relies on cell fate and on anteroposterior cell polarity. Development 124, 4193-4200. Abstract

Wrischnik, L.A., and Kenyon, C.J. (1997). The role of lin-22, a hairy/enhancer of split homolog, in patterning the peripheral nervous system of C. elegans. Development 124, 2875-2888. Abstract

Wu, J., Duggan, A., and Chalfie, M. (2001). Inhibition of touch cell fate by egl-44 and egl-46 in C. elegans. Genes Dev. 15, 789-802. Article

Xue, D., Tu, Y., and Chalfie, M. (1993). Cooperative interactions between the Caenorhabditis elegans homeoproteins UNC-86 and MEC-3. Science 261, 1324-1328. 
Yu, H., Pretot, R.F., Burglin, T.R., and Sternberg, P.W. (2003). Distinct roles of transcription factors EGL-46 and DAF-19 in specifying the functionality of a polycystin-expressing sensory neuron necessary for C. elegans male vulva location behavior. Development 130,5217-5227. Article

Yu, S., Avery, L., Baude, E., and Garbers, D.L. (1997). Guanylyl cyclase expression in specific sensory neurons: a new family of chemosensory receptors. Proc. Natl. Acad. Sci. USA 94, 3384-3387. Abstract Article

Zhang, S., Sokolchik, I., Blanco, G., and Sze, J.Y. (2004). Caenorhabditis elegans TRPV ion channel regulates 5HT biosynthesis in chemosensory neurons. Development 131, 1629-1638. Abstract Article

Zhang, Y., Ma, C., Delohery, T., Nasipak, B., Foat, B.C., Bounoutas, A., Bussemaker, H.J., Kim, S.K., and Chalfie, M. (2002). Identification of genes expressed in C. elegans touch receptor neurons. Nature 418, 331-335. Article

Zhou, H.M., and Walthall, W.W. (1998). UNC-55, an orphan nuclear hormone receptor, orchestrates synaptic specificity among two classes of motor neurons in Caenorhabditis elegans. J. Neurosci 18, 10438-10444. Abstract

All WormBook content, except where otherwise noted, is licensed under a Creative Commons Attribution License. 